\title{
Critical Stresses for Twinning, Slip, and Transformation in Ti-Based Shape Memory Alloys
}

\author{
A. Ojha ${ }^{1} \cdot$ H. Sehitoglu ${ }^{1}$
}

Published online: 28 March 2016

(C) ASM International 2016

\begin{abstract}
We investigate the effect of $\mathrm{Nb}$ and $\mathrm{Ta}$ contents on the (i) critical resolved shear stress (CRSS) for the $\beta-\alpha^{\prime \prime}$ transformation, (ii) the CRSS for austenite slip, and (iii) the CRSS for twin nucleation in martensite ( $\alpha^{\prime \prime}$ phase) that govern shape memory and superelasticity in Ti-based alloys. The critical stresses for slip and twinning are achieved with a modified Peierls Nabarro formalism utilizing generalized stacking fault energy and the generalized planar fault energy (GPFE), respectively, obtained from first-principles density functional theory (DFT) calculations. During the calculation of the twinning stress, we show the importance of the shuffling process in stabilizing and lowering the GPFE curve. Similarly, the transformation stress is obtained with heterogeneous martensite nucleation mechanism incorporating the energy barriers associated with the transformation process. Here, we point to the role of dislocations in the shuffling process during the early stage of transformation. We show that the increase of Ta content raises the CRSS more effectively for the case of slip compared to twinning or transformation. The slip stress and twin stress magnitudes increase with an increase in the unstable fault energy $\left(\gamma_{\text {us }}\right)$ and unstable twinning fault energy $\left(\gamma_{\mathrm{ut}}\right)$, respectively. In summary, as the Ta composition increases, the difference between martensite/austenite slip resistance and the transformation/ twinning stress widens showing the efficacy of Ta alloying additions.
\end{abstract}

H. Sehitoglu

huseyin@illinois.edu

1 Department of Mechanical Science and Engineering, University of Illinois at Urbana-Champaign, $1206 \mathrm{~W}$. Green Street, Urbana, IL 61801, USA
Keywords Superelasticity $\cdot \mathrm{Ti}-\mathrm{Nb}-\mathrm{Ta} \cdot$ Shape memory Transformation · Twinning - Slip $\cdot$ High temperature

\section{Introduction}

Ti-based shape memory alloys (SMAs) have received invigorated attention in recent years due to high temperature capabilities [1-6]. These alloys can also be exploited in biomedical applications $[7,8]$ removing the concerns with the use of nickel element in human body. Several experiments [1, 2, 6, 9], and recent theoretical calculations [10] have shown that upon alloying Ti-alloys with $\mathrm{Nb}$, Ta, and $\mathrm{Zr}$, high transformation strains (11\%) and high-martensite slip resistance can be achieved in addition to the high transformation temperatures (over $400 \mathrm{~K}$ ). There are four other parameters such as transformation stress, twinning stress, martensite slip stress, and austenite slip stress that govern the shape memory and superelastic behavior. An accurate determination of these parameters is crucial for the design of new SMAs. However, it is a tremendous experimental effort to determine these parameters for multiple alloys. Earlier experiments $[1,2,9,11]$ have revealed the role of composition on shape memory functionality in a selected number of Ti-based alloys. We note that further theoretical works encompassing a range of wide composition could cast further light on the generic trends of the composition effect on the martensite twinning, austenite slip, and the austenite to martensite transformation stress. In addition, the critical resolved shear stresses (CRSS) for martensite transformation, twinning, and austenite slip are the important parameters appearing in the constitutive equations [12] whether of the crystal plasticity type or continuum formulations, allowing description of SMAs response at the macroscales. With atomistic-informed 
modeling, the CRSS values can be precisely pinpointed in these alloys, which is the topic of the present paper.

Figure 1 shows the schematics of the four generic functionalities in Ti-based SMAs: (i) shape memory behavior via twinning/detwinning of orthorhombic martensite, (ii) superelastic response due to bcc-orthorhombic transformation, (iii) austenite slip, and (iv) martensite slip. In the case of shape memory behavior (i), when the internally twinned martensite variant is loaded above a critical stress, termed the "critical twinning stress, $\tau_{\mathrm{cr}}^{\mathrm{twin}}$," the martensite variant most favorably oriented to the loading direction grows at the expense of the other. The growth of the martensite variant occurs with the advances in the twin interfaces to form the end state called the "detwinned martensite." This process requires overcoming the twinning energy barrier represented by the generalized planar fault energy (GPFE). The GPFE is the energy per unit area required to nucleate a twin [13-15] and will be discussed later. Upon subsequent heating above the austenite finish $\left(\mathrm{A}_{\mathrm{f}}\right)$ temperature, the detwinned martensite reverts back to austenite, giving rise to shape memory effect. Upon loading further above the critical slip nucleation stress $\left(\tau_{\text {mar }}^{\mathrm{s}}\right)$, slip dislocations may nucleate in the martensite phase that curtails reversibility due to plastic strain accumulation. If the crystal is unloaded before the martensite slip nucleation stress, a large strain may be recovered in this case. Similarly, for the case of superelastic response (ii), the initial austenite phase transforms to the martensite above a critical stress, termed the "critical transformation stress, $\tau_{\mathrm{cr}}^{\text {trans }}$," and reverts back to austenite upon unloading. At a very high temperature $\left(T \gg \mathrm{A}_{\mathrm{f}}\right)$, slip is commonly observed in austenite upon loading above a critical stress, $\tau_{\text {aus }}^{\mathrm{s}}$, and no strain is recovered in this case. In order to achieve a high transformation strain, it is desirable to minimize irreversible plastic strain accumulation through increasing austenite and martensite dislocation slip resistance. Concurrently, it is important to lower the transformation and twinning stresses to assist the thermoelastic martensite transformation. In other words, the difference between the austenite/martensite slip resistance and the transformation/twinning stress is an important parameter that governs the shape memory or superelastic response.

Research on $\mathrm{Ti}-\mathrm{Nb}$ alloys can be classified into two categories. The works on plastic deformation mechanisms examined slip and twinning, and the second set of works considered the shape memory behavior (the transformation from the bcc to orthorhombic phase). Both class of studies uncovered the physical mechanisms governing the deformation utilizing microscopic tools such as transmission electron microscopy (TEM) and with experiments at macroscale. The works on slip and twinning using TEM investigations [16] have revealed the similarities between $\beta$ Tibased alloys and pure bcc metals. The TEM analysis on $\mathrm{Ti}-$ $4.4 \mathrm{Ta}-1.9 \mathrm{Nb}$ alloy [17] investigated the role of the microstructural variations, slip, and twinning, and the role of austenite/martensite interface on the strength and ductility. Experiments [16] have successfully revealed the slip systems in $\beta$ Ti-based alloys allowing an in-depth understanding on the mobility of slip dislocations, cross-slip mechanism, and dislocation-interstitial interactions. Specially, the role of interstitials such as $\mathrm{Si}$ and $\mathrm{O}$ on the strength

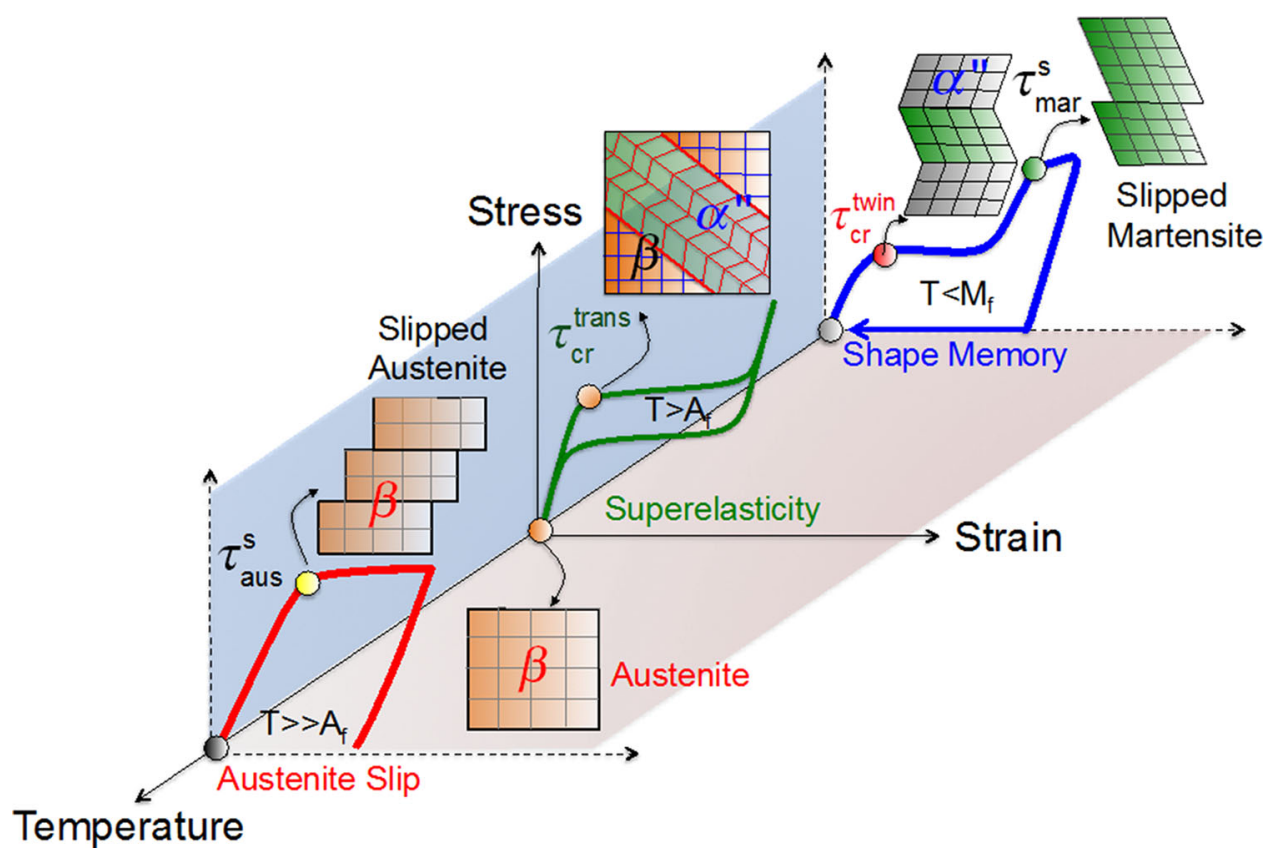

Fig. 1 Stress-strain response showing shape memory effect, superelasticity, martensite slip, and austenite slip as a function of temperature in $\mathrm{Ti}-\mathrm{Nb}-\mathrm{Ta}$ alloy 
of Ti-based alloys has been discussed in detail. In addition, the role of alloying elements such as $\mathrm{Cr}$ and In $[18,19]$ in governing slip, twinning, and transformation, and their influence on grain refining process have also been studied.

Experiments at macroscale have revealed the role of alloying elements such as $\mathrm{Ta}, \mathrm{Zr}$, and $\mathrm{Nb}[1-4,6,9,11,20$, 21] on shape memory and superelastic properties in several Ti-based alloys. Of particular interests are establishing the parameters such as transformation stress and temperature, and slip stresses that affect the recoverable strains, and consequently optimizing the composition to achieve better shape memory performance at high temperatures. Therefore, there is a need for theoretical models to establish these quantities accurately. We point out that the theoretical considerations at the atomic level can establish the critical slip, transformation, and twinning stresses thus guiding the development of these alloys. In this regard, the current work aims at establishing (i) the CRSS for bcc $(\beta)$ to orthorhombic $\left(\alpha^{\prime \prime}\right)$ transformation $\left(\tau_{\mathrm{cr}}^{\text {trans }}\right)$ noting that the superelasticity is achieved by means of a reversible thermoelastic martensite transformation between these two phases, (ii) the CRSS for martensite twinning $\left(\tau_{\mathrm{cr}}^{\mathrm{twin}}\right)$, and (iii) the CRSS for austenite slip, $\tau_{\text {aus }}^{\mathrm{s}}$. The critical transformation stress (i) is achieved with a dislocation-based heterogeneous mechanism utilizing the Peierls Nabarro (PN) formalism [22-28] incorporating the energy barriers associated with the transformation process. We consider the coupled transformation components-Bain deformation and the shuffling process-and the accompanying dislocation activities that participate in the transformation process. The shuffling mechanism during the transformation locally rearranges the atomic positions in the bcc crystal to match the stacking sequence of the orthorhombic crystal. Similarly, we carefully point to the shuffling process during the course of obtaining the martensite twinning stress (ii). As will be discussed later, twinning on $\{110\}\langle 110\rangle$ system in Ti-alloys is accomplished through shear followed by shuffle mechanism, while twinning on $\{111\}$ is accomplished through shear alone. When obtaining the energy barriers (GPFE) associated with twinning, we show that shuffling mechanism is an integral part in the twinning process as it both lowers and stabilizes the GPFE curve. Similarly, in order to calculate the CRSS for austenite slip, we obtain the generalized stacking fault energy (GSFE) [29], and utilize it to calculate the Peierls stress. Overall, we investigate the aforesaid parameters (i, ii, and iii) in Ti-based alloys for 11 different compositions of $\mathrm{Nb}$ and $\mathrm{Ta}$ (in at.\%) exhibiting the minimum and maximum transformation strains. The minimum and maximum transformation strains for different alloying compositions were obtained using lattice deformation theory in our previous work [10].
The importance of austenite slip during martensitic transformation has been well recognized in NiTi [30-32]. It has been observed that slip dislocations nucleate during transformation process due to high internal stresses and strains along the austenite/martensite interfaces [33]. It is suggested that these dislocations, in most of the cases, deteriorate the shape memory properties by introducing permanent plastic strain, while in some other cases, they are found to assist the martensite transformation, as in the case of CuAlNi [34]. In order to better understand the role of dislocations in martensite transformation, the CRSS for slip has to be established. In the present work, we identify a set of variables that govern the slip in addition to twinning and transformation stresses in Ti-based alloys noting that these parameters have not been discussed in great detail in the literature. Most importantly, we note that the change in the compositions in Ti-based alloys affects the twinning/transformation stress by changing the twinning shear magnitudes, burgers vector, the lattice constants, the elastic moduli, and the shuffle magnitudes. We provide these quantities in the current work for the compositions under consideration. Although binary $\mathrm{Ti}-\mathrm{Nb}$ alloys are found to exhibit high transformation temperatures, nonetheless the maximum transformation strains in these alloys are below $3 \%[1,6]$. The advantage of Ta addition is that it increases the CRSS for martensite and austenite slip nucleation so that a large reversible deformation can be achieved without significant plastic strain accumulation. Recently, theoretical works [10] have established the transformation strains and the CRSS for slip in a large number of $\mathrm{Ti}-\mathrm{Nb}-\mathrm{Ta}$ alloys. The maximum transformation strain obtained theoretically is $6.5 \%$ in Ti$6.25 \mathrm{Nb}-6.25 \mathrm{Ta}$ [10]. The lowest CRSS for martensite slip was $127 \mathrm{MPa}$ in $\mathrm{Ti}-6.25 \mathrm{Nb}-6.25 \mathrm{Ta}$ and the maximum CRSS was $283 \mathrm{MPa}$ in Ti-25Nb-25Ta, more than twice the increase in the CRSS upon alloying $\mathrm{Ti}$ with $\mathrm{Nb}$ and $\mathrm{Ta}$. We note that alloying does not produce similar effect on slip, transformation and twinning stresses, and this demands a correct model for determining these quantities theoretically, which we undertake in the present study.

We organize the paper as follows. In "Simulation Methods and Lattice Constants," "Generalized Stacking Fault Energy and Austenite Slip," "Generalized Planar Fault Energy and Twinning," and "BCC $(\beta) \rightarrow$ Orthorhombic $\left(\alpha^{\prime \prime}\right)$ Transformation" sections, we discuss, respectively, our simulation methods, the austenite slip stress modeling, the twinning stress modeling, and the transformation stress modeling approaches. In these sections, we also provide discussions on obtaining the GPFE for orthorhombic B19 $\left(\alpha^{\prime \prime}\right)$ martensite twinning and the energy barriers associated with the transformation process. In "Discussion of the Results" section, we provide discussion and implications of the results, and finally provide a conclusion in "Conclusion" section. 


\section{Simulation Methods and Lattice Constants}

We used the first-principles DFT calculations to compute the total structural energy of the crystal. The DFT was implemented using the Vienna ab initio Simulations Package (VASP) with the projector augmented wave (PAW) method and the generalized gradient approximation (GGA) [35, 36]. A $4 \times 4 \times 2$ supercell consisting of 64 atoms was used for simulating a disordered $\beta$ crystal, and the $\mathrm{Ti}, \mathrm{Nb}$, and $\mathrm{Ta}$ atoms were positioned randomly within the supercell depending on the composition and the bcc crystal coordinates. Independent simulations with number of atoms ranging from 16 to 96 were implemented to ensure that 64 atoms supercell was large enough to obtain the converged minimum structural energy value. In addition, to see the effect of the random positions of atoms, four independent cases representing four different random solid solution alloys were used to obtain the lattice constants and the minimum structural energies. The variation of the lattice constant and the structural energy due to random alloy positioning was within $0.5 \%$ agreement. The MonkhorstPack $k$-point mesh for the Brillouin-zone integration used was $6 \times 6 \times 12$, and the convergence was verified. Note that the $k$-points chosen are inversely proportional to the ratio of the lattice vectors of the supercell for uniform sampling of the $k$-space. Similar procedure was followed for GSFE and GPFE calculations of B19 orthorhombic structure. Ionic relaxation was performed by a conjugate gradient algorithm. The energy cut-off of $360 \mathrm{eV}$ was used for the plane-wave basis set. The total energy was converged to less than $10^{-5} \mathrm{eV}$ per atom. For GSFE calculations, a full internal atom relaxation, including perpendicular and parallel directions to the fault plane, was allowed for minimizing the short-range interaction between misfitted layers in the vicinity of the fault plane.

\section{Lattice Constant Calculations}

The lattice constants for $\beta \mathrm{Ti}-\mathrm{Nb}-\mathrm{Ta}$ alloys are calculated by minimizing the total structural energy as a function of the varying lattice parameters. The equilibrium lattice constant $\left(a_{0}\right)$ is then obtained as the one corresponding to the minimum structural energy. Similarly, for the case of orthorhombic crystal, the three lattice constants $(a, b, c)$ are obtained in two following steps: (i) first, by obtaining the equilibrium volume $\left(V_{0}\right)$ of the lattice and (ii) second, by varying the $a / c$ and $b / c$ ratios for the calculated equilibrium volume $\left(V_{0}\right)$ of the crystal for the angles $\alpha=\beta=\gamma=\pi / 2$. For complete details on lattice constant calculations, see Ref [10]. Table 1 represents the complete list of equilibrium lattice constants of $\mathrm{Ti}-\mathrm{Nb}-\mathrm{Ta}$ alloys considered in the present analysis. It should be noted from Table 1 that increasing Ta content does not have significant effect on lattice constants of $\beta$ phase.

\section{Results}

\section{Generalized Stacking Fault Energy and Austenite Slip}

In order to achieve high transformation strains, it is desirable to minimize plastic strain accumulating through austenite slip. The slip in $\beta$ Ti-based alloys occur on $\{110\}\langle 111\rangle$ system similar to bcc metals $[16,37]$, and we are interested in obtaining the energy barriers (GSFE) required to nucleate a $1 / 2\langle 111\rangle$ dislocation on $\{110\}$ plane. The GSFE can be obtained by rigidly shearing one half of the crystal relative to the other half on the $\{110\}$ plane along $\langle 111\rangle$ direction by displacement of $u=n \mathrm{~b}$, where $\mathrm{b}$ is the magnitude of the Burgers vector of the slip dislocation and $n$ is the parameter ranging from 0 to 1 [29].
Table 1 Lattice constants $\left(a_{0}\right)$ of $\beta$ and orthorhombic phases $(a, b, c)$ of $\mathrm{Ti}-\mathrm{Nb}-\mathrm{Ta}$ alloys

\begin{tabular}{|c|c|c|c|c|c|c|c|c|}
\hline \multirow[t]{2}{*}{ Alloys } & \multicolumn{4}{|c|}{ Theory (this study) } & \multicolumn{4}{|c|}{ Experiments } \\
\hline & $a_{0}$ & $a$ & $b$ & $c$ & $\mathrm{a}_{0}$ & $a$ & $b$ & $c$ \\
\hline $\mathrm{Ti}-6.25 \mathrm{Nb}-6.25 \mathrm{Ta}$ & 3.26 & 3.06 & 4.66 & 4.93 & - & - & - & - \\
\hline $\mathrm{Ti}-6.25 \mathrm{Nb}-18.75 \mathrm{Ta}$ & 3.26 & 3.15 & 4.64 & 4.81 & - & 3.16 & 4.64 & 4.83 \\
\hline $\mathrm{Ti}-18.75 \mathrm{Nb}-25 \mathrm{Ta}$ & 3.26 & 3.27 & 4.66 & 4.72 & - & - & - & - \\
\hline $\mathrm{Ti}-25 \mathrm{Nb}-25 \mathrm{Ta}$ & 3.27 & 3.28 & 4.66 & 4.71 & - & - & - & - \\
\hline $\mathrm{Ti}-12.5 \mathrm{Nb}-37.5 \mathrm{Ta}$ & 3.27 & 3.25 & 4.66 & 4.71 & - & - & - & - \\
\hline $\mathrm{Ti}-12.5 \mathrm{Nb}$ & 3.26 & 3.01 & 4.65 & 4.95 & 3.28 & 3.02 & 4.66 & 4.98 \\
\hline $\mathrm{Ti}-25 \mathrm{Nb}$ & 3.26 & 3.17 & 4.62 & 4.76 & 3.28 & 3.19 & 4.63 & 4.79 \\
\hline $\mathrm{Ti}-18.75 \mathrm{Nb}$ & 3.26 & 3.09 & 4.63 & 4.87 & - & - & - & - \\
\hline $\mathrm{Ti}-25 \mathrm{Ta}$ & 3.26 & 3.28 & 4.45 & 4.48 & - & - & - & - \\
\hline Ti-31.25Ta & 3.27 & 3.29 & 4.46 & 4.50 & - & - & - & - \\
\hline $\mathrm{Ti}-37.5 \mathrm{Ta}$ & 3.27 & 3.31 & 4.47 & 4.50 & - & - & - & - \\
\hline
\end{tabular}

The spaces marked with dash (-) represent unavailable experimental data. Note that the experimental [1] compositions are close (not exact) to theoretical compositions for lattice constant comparison 


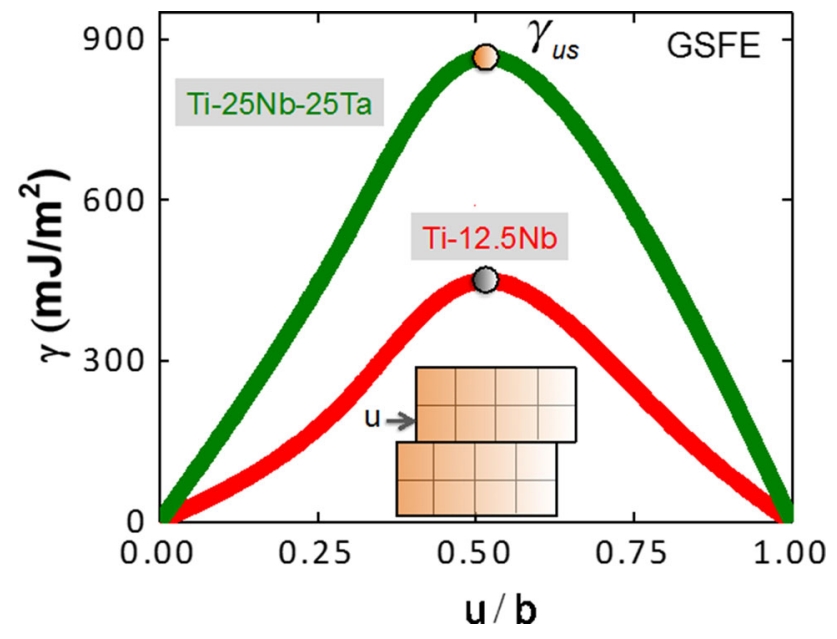

Fig. 2 The $\{110\}\langle 111\rangle$ GSFE for Ti-Nb-Ta alloys exhibiting the maximum and minimum values

Figure 2 shows the GSFE for two alloying compositions$\mathrm{Ti}-12.5 \mathrm{Nb}$ and $\mathrm{Ti}-25 \mathrm{Nb}-25 \mathrm{Ta}$ exhibiting the minimum and maximum energy barriers respectively among all the compositions considered in the current paper. The term $\gamma_{\text {us }}$ in Fig. 2 corresponds to the energy at displacement $u=0.5 \mathrm{~b}$, and represents the maximum energy barrier required to nucleate a slip. The $\{110\}\langle 111\rangle$ shear modulus can also be obtained from the GSFE curve using the equation, $G_{\{110\}\langle 111\rangle}=\left.2 \pi \frac{\partial \gamma}{\partial u}\right|_{\max }$. A complete list of $\{110\}\langle 111\rangle \gamma_{\text {us }}$ values and the shear moduli for all of the compositions are listed in Table 2. For comparison, the $\{100\}\langle 100\rangle \gamma_{\text {us }}$ values for martensite slip, and the shear moduli we obtained in our previous works [10] are also included in Table 2.

The modified Peierls Nabarro formalism [28, 38] is adopted in the present work to calculate the CRSS for austenite slip. The PN formalism allows us to derive the CRSS by obtaining the maximum slope of the misfit energy variation with respect to the dislocation position. The misfit energy across a slip plane is defined as the sum over energy contributions due to slip between pairs of atomic planes $[24,27]$, and can be obtained from the GSFE as follows:

$E_{\gamma}^{\mathrm{s}}=\int_{-\infty}^{+\infty} \gamma_{\mathrm{GSFE}}(f(x)) d x$

The term $\gamma_{\mathrm{GSFE}}$ is the GSFE energy landscape expressed in sinusoidal form, $f(x)$ is defined as the disregistry function which is a measure of the slip distribution on the slip plane. The solution to $f(x)$ can be written as follows [24, 27]:

$f(x)=\frac{b}{\pi}\left(\tan ^{-1}\left(\frac{x}{\xi}\right)\right)+\frac{b}{2}$,

where $b$ is the magnitude of the Burgers vector of the slip dislocation, $x$ is the position of the dislocation line, and $\xi$ is the half-core width of the dislocation given by $d /$ $(2(1-v))$, where $d$ is the slip plane interplanar distance and $v$ is the Poisson ratio. The discrete form of Eq. (1) can be written as follows:

$E_{\gamma}^{\mathrm{s}}=\sum_{m=-\infty}^{m=+\infty} \gamma_{\mathrm{GSFE}}\left(f\left(m a^{\prime}-u\right)\right) a^{\prime}$,

where $m$ is an integer, $u$ is the position of the dislocation line, and $a^{\prime}$ is the lattice periodicity defined as the shortest distance between two equivalent atomic rows in the direction of the dislocation displacement. The Peierls stress is calculated as the maximum slope of the misfit energy curve which describes the potential energy of the dislocation as a function of the dislocation position $u$, and can be written as follows:

$\tau_{\text {critical }}^{\text {slip }}=\frac{1}{b} \max \left(\frac{\partial E_{\gamma}^{\mathrm{s}}}{\partial u}\right)$.

The values of the CRSS for austenite slip obtained using Eq. (4) are given in Table 3. It is important to point out that higher the $\gamma_{\mathrm{us}}$, higher is the CRSS for slip nucleation in both austenite and martensite phases in $\mathrm{Ti}-\mathrm{Nb}-\mathrm{Ta}$ alloys.

\section{Generalized Planar Fault Energy and Twinning}

When the internally twinned martensite with multiple variants is loaded above the critical twinning stress $\tau_{\mathrm{cr}}^{\mathrm{twin}}$, the variant most favorable to the loading orientation grows at the expense of the other (see Fig. 1). The growth of the martensite occurs through the advancements of the twin interfaces, and is governed by the GPFE. Twinning in the $\mathrm{Ti}-\mathrm{Nb}$ orthorhombic crystal is observed on $\{111\}[39,40]$ and $\{110\}$ planes [41], as validated by experimental measurements. In the present analysis, we consider obtaining the twinning stresses for both the twin systems. In Fig. 3, we consider a schematic of an orthorhombic crystal oriented along the $x=[01 \overline{1}], y=[011]$, and $z=[100]$ directions. During the shearing process to form a twin, the dislocations overcome an energy barrier per unit area, termed the GPFE [13-15]. In our calculations, we observed that imposing pure shear alone as in Fig. 3a to form a twinned crystal is energetically unstable, as the energy barriers continuously increase upon shearing successive layers. Therefore, additional shuffle is required to create a stable twinned structure as shown in Fig. 3b. However, for the case of $\{111\}$ twin, no shuffle is required, and the application of pure shear alone is sufficient to obtain the stable minimum GPFE values.

In Fig. 4a, we show the energy variation of the sheared structure when shuffle displacements of varying magnitudes are applied on $\{010\}\langle 001\rangle$ atoms of the B19 


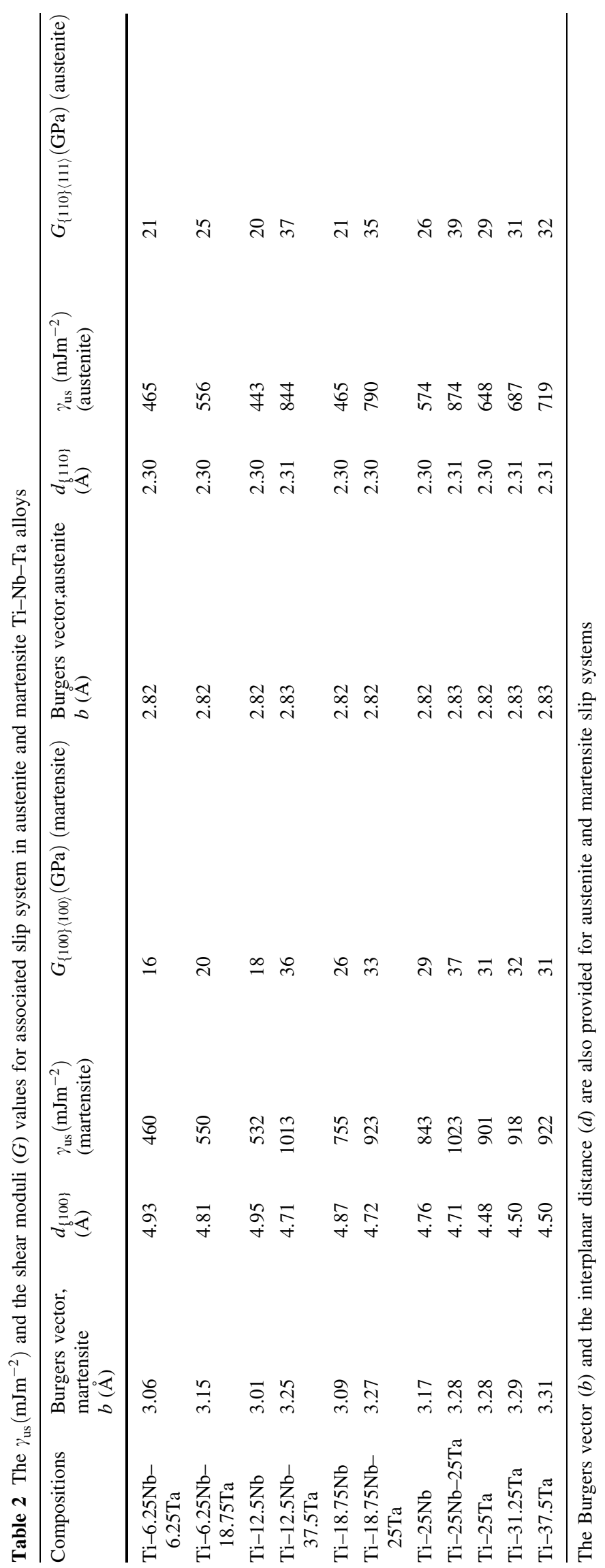


Table 3 Alloy compositions and the CRSS for martensite twinning, martensite slip, austenite slip, and transformation

\begin{tabular}{|c|c|c|c|c|c|}
\hline Alloy compositions & $\begin{array}{l}\{111\} \text { Twinning stress } \\
\text { Martensite }\left(\tau_{\mathrm{cr}}^{\mathrm{twin}}, \mathrm{MPa}\right)\end{array}$ & $\begin{array}{l}\{110\} \text { Twinning stress } \\
\text { Martensite } \\
\left(\tau_{\mathrm{cr}}^{\mathrm{twin}}, \mathrm{MPa}\right)\end{array}$ & $\begin{array}{l}\text { Critical slip stress } \\
\text { Martensite } \\
\left(\tau_{\text {mar }}^{\mathrm{s}}, \mathrm{MPa}\right)\end{array}$ & $\begin{array}{l}\text { Critical transformation } \\
\text { Stress } \\
\left(\tau_{\mathrm{cr}}^{\text {trans }}, \mathrm{MPa}\right)\end{array}$ & $\begin{array}{l}\text { Critical slip stress } \\
\text { Austenite } \\
\left(\tau_{\text {aus }}^{\mathrm{s}}, \mathrm{MPa}\right)\end{array}$ \\
\hline $\mathrm{Ti}-6.25 \mathrm{Nb}-6.25 \mathrm{Ta}$ & 101 & 94 & 127 & 74 & 135 \\
\hline $\mathrm{Ti}-6.25 \mathrm{Nb}-18.75 \mathrm{Ta}$ & 118 & 106 & 152 & 87 & 161 \\
\hline $\mathrm{Ti}-12.5 \mathrm{Nb}$ & 93 & 99 & 144 & 83 & 129 \\
\hline $\mathrm{Ti}-12.5 \mathrm{Nb}-37.5 \mathrm{Ta}$ & 131 & 124 & 280 & 119 & 245 \\
\hline $\mathrm{Ti}-18.75 \mathrm{Nb}$ & 80 & 84 & 196 & 88 & 136 \\
\hline $\mathrm{Ti}-18.75 \mathrm{Nb}-25 \mathrm{Ta}$ & 88 & 93 & 255 & 92 & 230 \\
\hline $\mathrm{Ti}-25 \mathrm{Nb}$ & 72 & 74 & 228 & 76 & 167 \\
\hline $\mathrm{Ti}-25 \mathrm{Nb}-25 \mathrm{Ta}$ & 83 & 91 & 283 & 96 & 254 \\
\hline $\mathrm{Ti}-25 \mathrm{Ta}$ & 82 & 89 & 266 & 69 & 188 \\
\hline $\mathrm{Ti}-31.25 \mathrm{Ta}$ & 87 & 93 & 273 & 73 & 198 \\
\hline $\mathrm{Ti}-37.5 \mathrm{Ta}$ & 87 & 96 & 278 & 75 & 211 \\
\hline
\end{tabular}

Fig. 3 a Twinning in an orthorhombic crystal on $\{011\}\langle 011\rangle$ system. b A stable twin formed after coupled shear and shuffle

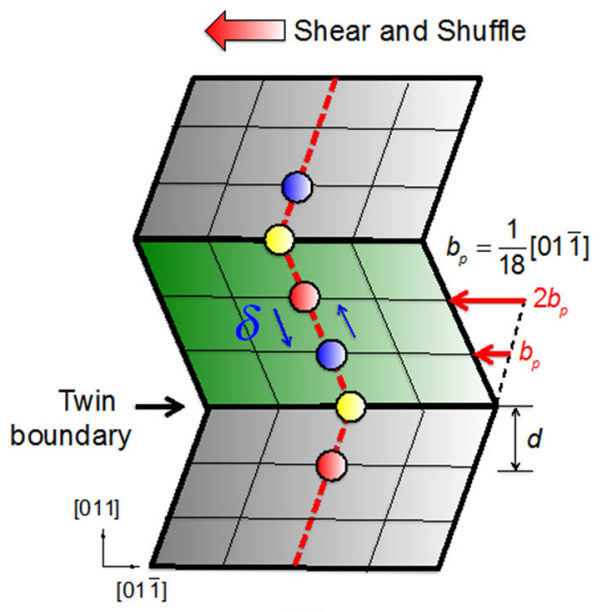

(a)

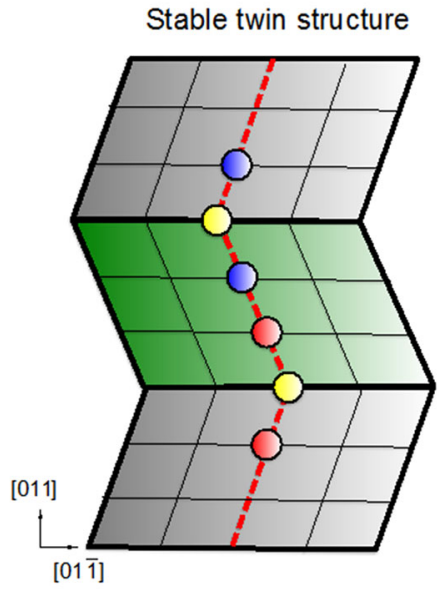

(b)
Fig. 4 a Structural energy variation of an orthorhombic crystal with respect to shuffle displacements. b Shuffling of atoms on (010) plane along $\langle 001\rangle$ direction

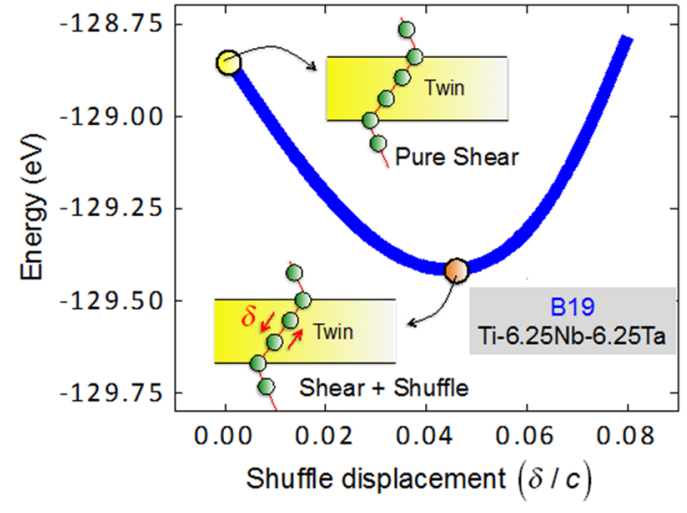

(a)

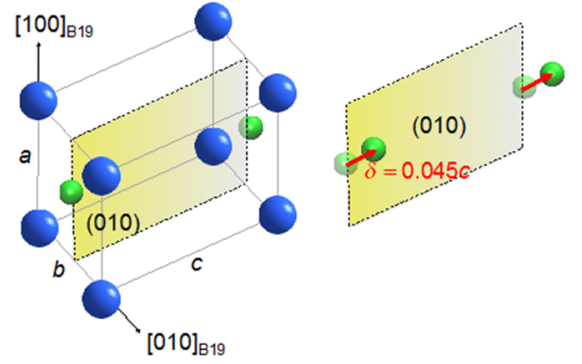

(b) structure. The $\{001\}\langle 001\rangle_{\mathrm{B} 19}$ system is shown in Fig. 4 b. An increase in shuffle displacement magnitude decreases the overall energy of the sheared structure, and a minimum structural energy is obtained when the shuffle displacement is $\delta=0.045 c$ for the case of Ti-6.25Nb-6.25Ta where $c$ is the largest lattice parameter of martensite. In Table 4, we 
Table 4 The magnitude of Burgers vector of twinning partial $(b)$, twinning shear magnitude $(s)$, shuffling magnitude and $\langle 110\rangle$ shear moduli $(G)$ of $\mathrm{Ti}-\mathrm{Nb}-\mathrm{Ta}$ alloys

\begin{tabular}{lllll}
\hline Compositions & $b(\AA)$ & Twinning shear $(s)$ & Shuffle magnitude $\delta(\AA)$ & $\mathrm{G}_{\{110\}\langle 110\rangle}(\mathrm{GPa})$ \\
\hline $\mathrm{Ti}-6.25 \mathrm{Nb}-6.25 \mathrm{Ta}$ & 0.54 & 0.17 & 0.22 & 21 \\
$\mathrm{Ti}-6.25 \mathrm{Nb}-18.75 \mathrm{Ta}$ & 0.52 & 0.16 & 0.22 & 23 \\
$\mathrm{Ti}-12.5 \mathrm{Nb}$ & 0.54 & 0.17 & 0.23 & 22 \\
$\mathrm{Ti}-12.5 \mathrm{Nb}-37.5 \mathrm{Ta}$ & 0.52 & 0.16 & 0.22 & 34 \\
$\mathrm{Ti}-18.75 \mathrm{Nb}$ & 0.52 & 0.16 & 0.21 & 22 \\
$\mathrm{Ti}-18.75 \mathrm{Nb}-25 \mathrm{Ta}$ & 0.52 & 0.16 & 0.23 & 31 \\
$\mathrm{Ti}-25 \mathrm{Nb}$ & 0.52 & 0.16 & 0.21 & 29 \\
$\mathrm{Ti}-25 \mathrm{Nb}-25 \mathrm{Ta}$ & 0.52 & 0.16 & 0.23 & 35 \\
$\mathrm{Ti}-25 \mathrm{Ta}$ & 0.50 & 0.15 & 0.21 & 27 \\
$\mathrm{Ti}-31.25 \mathrm{Ta}$ & 0.50 & 0.15 & 0.22 & 30 \\
$\mathrm{Ti}-37.5 \mathrm{Ta}$ & 0.50 & 0.15 & 0.22 & 29 \\
\hline
\end{tabular}

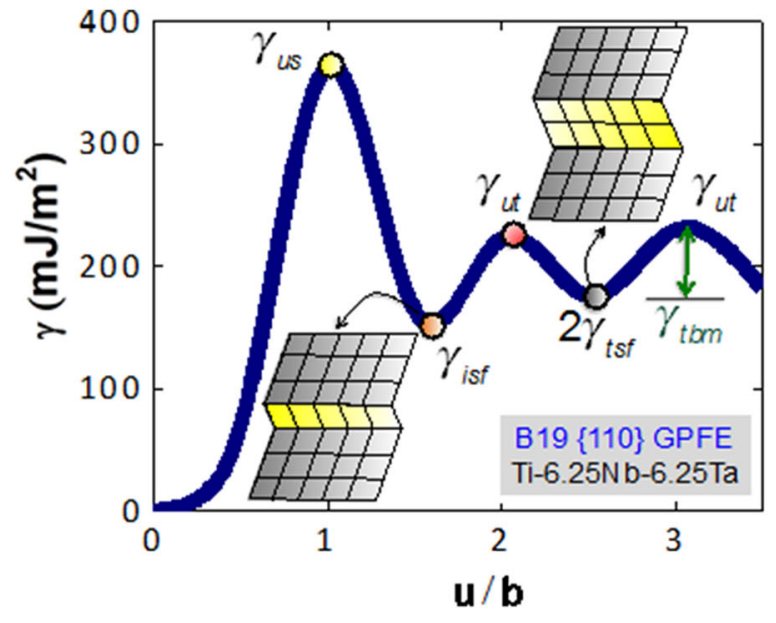

(a)

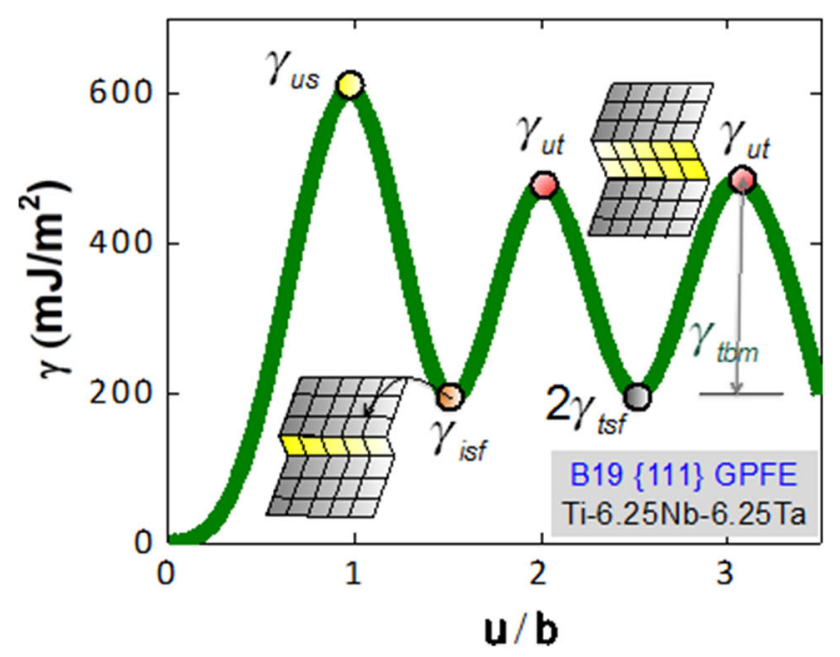

(b)

Fig. 5 GPFE for twinning on $\mathbf{a}\{110\}$ and $\mathbf{b}\{111\}$ planes in an orthorhombic Ti-6.25Nb-6.25Ta alloy
Table 5 The energy values (in $\mathrm{mJm}^{-2}$ ) associated with the $\{110\}<110>$ GPFE for Ti-Nb-Ta alloys

\begin{tabular}{lllll}
\hline Compositions & $\gamma_{\text {us }}$ & $\gamma_{\text {isf }}$ & $\gamma_{\text {ut }}$ & $2 \gamma_{\text {tsf }}$ \\
\hline Ti-6.25Nb-6.25Ta & 364 & 165 & 223 & 176 \\
Ti-6.25Nb-18.75Ta & 393 & 251 & 281 & 267 \\
Ti-12.5Nb & 415 & 226 & 276 & 273 \\
Ti-12.5Nb-37.5Ta & 409 & 244 & 289 & 263 \\
Ti-18.75Nb & 351 & 120 & 167 & 176 \\
Ti-18.75Nb-25Ta & 393 & 236 & 297 & 246 \\
Ti-25Nb & 312 & 123 & 160 & 111 \\
Ti-25Nb-25Ta & 344 & 187 & 228 & 176 \\
Ti-25Ta & 394 & 231 & 296 & 241 \\
Ti-31.25Ta & 394 & 233 & 296 & 241 \\
Ti-37.5Ta & 396 & 232 & 300 & 256 \\
\hline
\end{tabular}

provide the twinning shear magnitudes, the Burgers vector of the twinning partial, and the shuffling displacement magnitudes. The $\{110\}$ GPFE with imposed shuffle for the case of Ti-6.26Nb-6.25Ta is shown in Fig. 5a. Similarly, the GPFE for the case of $\{111\}$ twin is shown in Fig. 5b. The term $\gamma_{\text {us }}$ represents the energy barrier required to nucleate the first layer stacking fault. Similarly, the term $\gamma_{\mathrm{ut}}$ represents the energy barrier required to grow the twin, $2 \gamma_{\text {tsf }}$ represents the stable energy fault corresponding to the 2nd layer fault, and $\gamma_{\mathrm{tbm}}$ is the twin boundary migration energy given by $\gamma_{\mathrm{tbm}}=\gamma_{\mathrm{ut}}-2 \gamma_{\mathrm{tsf}}$. A complete list of energy values for all other alloys is included in Table 5. In Table 6, we provide a list of parameters governing $\{111\}$ twinning in $\mathrm{Ti}-\mathrm{Nb}$-based alloys.

\section{Modeling of the Twinning Stress}

We have developed a twinning stress model using the modified Peierls Nabarro formalism [for more details, see 
Table 6 The Burgers vector of the twinning partial on $\{111\}$ plane for orthorhombic martensite the $\{111\}$ interplanar distance, the twinning shear $(s)$, the shear moduli, and the $\gamma_{\mathrm{ut}}\left(\mathrm{mJm}^{-2}\right)$ values for Ti-Nb-Ta alloys

\begin{tabular}{|c|c|c|c|c|c|c|}
\hline Compositions & Burgers vector $(b)$ & $|b|(\stackrel{\circ}{\mathrm{A}}$ & $d_{\{111\}}\left(\begin{array}{c}\mathrm{o} \\
\mathrm{A}\end{array}\right)$ & Twinning shear $(s)$ & Shear modulus (GPa) & $\gamma_{\mathrm{ut}}\left(\mathrm{mJm}^{-2}\right)$ \\
\hline $\mathrm{Ti}-6.25 \mathrm{Nb}-6.25 \mathrm{Ta}$ & {$\left[\begin{array}{lll}-0.2832 & -0.3562 & 0.0730\end{array}\right]$} & 2.3 & 3.72 & 0.62 & 22 & 476 \\
\hline $\mathrm{Ti}-6.25 \mathrm{Nb}-18.75 \mathrm{Ta}$ & {$\left[\begin{array}{lll}-0.3671 & -0.4148 & 0.0477\end{array}\right]$} & 2.2 & 3.69 & 0.60 & 28 & 479 \\
\hline $\mathrm{Ti}-12.5 \mathrm{Nb}$ & {$\left[\begin{array}{lll}-0.2503 & -0.3354 & 0.0850\end{array}\right]$} & 2.2 & 3.71 & 0.60 & 27 & 469 \\
\hline $\mathrm{Ti}-12.5 \mathrm{Nb}-37.5 \mathrm{Ta}$ & {$\left[\begin{array}{lll}-0.4455 & -0.4771 & 0.0316\end{array}\right]$} & 1.45 & 3.69 & 0.40 & 28 & 498 \\
\hline $\mathrm{Ti}-18.75 \mathrm{Nb}$ & {$\left[\begin{array}{lll}-0.3199 & -0.3787 & 0.0588\end{array}\right]$} & 2.3 & 3.70 & 0.62 & 16 & 363 \\
\hline $\mathrm{Ti}-18.75 \mathrm{Nb}-25 \mathrm{Ta}$ & {$\left[\begin{array}{lll}-0.4559 & -0.4802 & 0.0243\end{array}\right]$} & 1.63 & 3.71 & 0.44 & 29 & 456 \\
\hline $\mathrm{Ti}-25 \mathrm{Nb}$ & {$\left[\begin{array}{lll}-0.3941 & -0.4336 & 0.0395\end{array}\right]$} & 2.13 & 3.69 & 0.58 & 16 & 350 \\
\hline $\mathrm{Ti}-25 \mathrm{Nb}-25 \mathrm{Ta}$ & {$\left[\begin{array}{lll}-0.4642 & -0.4864 & 0.0221\end{array}\right]$} & 1.51 & 3.72 & 0.41 & 22 & 393 \\
\hline $\mathrm{Ti}-25 \mathrm{Ta}$ & {$\left[\begin{array}{llll}-0.5636 & -0.5397 & -0.0239\end{array}\right]$} & 1.33 & 3.70 & 0.36 & 29 & 389 \\
\hline $\mathrm{Ti}-31.25 \mathrm{Ta}$ & {$\left[\begin{array}{llll}-0.5631 & -0.5372 & -0.0259\end{array}\right]$} & 1.53 & 3.70 & 0.41 & 29 & 435 \\
\hline $\mathrm{Ti}-37.5 \mathrm{Ta}$ & {$\left[\begin{array}{l}-0.5734-0.5446-0.0287] \\
\end{array}\right.$} & 1.36 & 3.71 & 0.37 & 30 & 441 \\
\hline
\end{tabular}

Fig. 6 Twin dislocation arrangement in an orthorhombic crystal on $\{111\}$ plane

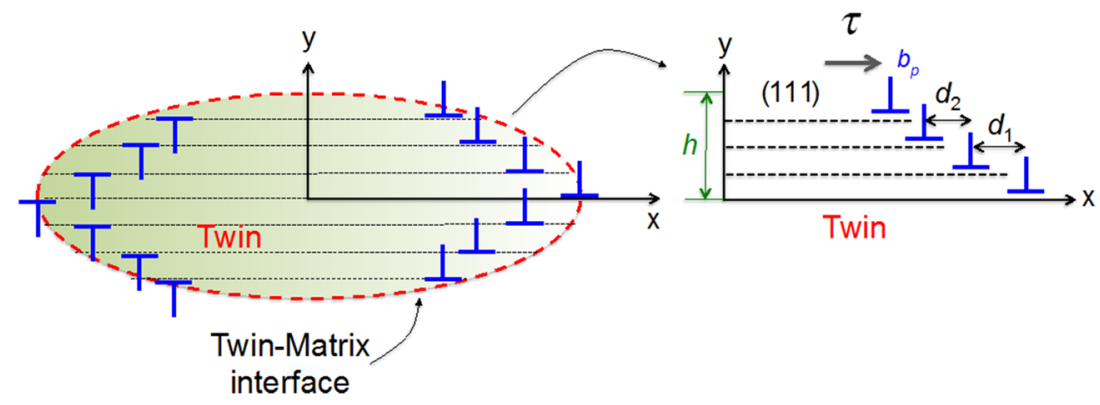

[28, 38]]. Consider the dislocation arrangement of a lenticular twin as shown in Fig. 6. We obtain the twinning stress by considering the total energy of the dislocations, and minimizing it with respect to separation distances $d_{1}$ and $d_{2}$. The total energy of the twin nucleus corresponding to Fig. 6 can be written as follows:

$E_{\text {total }}=E_{\text {int }}+E_{\mathrm{GPFE}}+E_{\text {line }}-W$,

where $E_{\text {int }}$ is the interaction energy of the dislocations, $E_{\mathrm{GPFE}}$ is the twin boundary energy, $E_{\text {line }}$ is the dislocation line energy, and $W$ is the externally applied stress. Upon substituting each of the energy terms in Eq. (5), we have the following:

$$
\begin{aligned}
& E_{\text {total }}=-\frac{\mu b^{2}}{2 \pi}\left\{\ln \left(\frac{d_{2}}{r_{o}}\right)+\ln \left(\frac{d_{1}+d_{2}}{r_{o}}\right)+\ln \left(\frac{d_{1}}{r_{o}}\right)\right\} \\
& +\sum_{\substack{m=-\infty \\
i=2}}^{m=+\infty} \gamma_{\text {twin }}\left(f\left(m a^{\prime}-u\right)\right) a^{\prime}+N \frac{\mu b^{2}}{2(1-v)}\left(1-v \cos ^{2} \theta\right) \\
& +\sum_{i=1}^{i s h d_{i}}
\end{aligned}
$$

Here $h$ is the height of the twin nucleus, $s$ is the twinning shear defined as $b / d$, and $r_{\mathrm{o}}$ is the core width determined as $d_{\{111\}} /(1-\mathrm{v})$. The terms $m, a,^{\prime}$ and $u$ are described earlier in Eq. (3). The twinning stress is then obtained by minimizing the total energy with respect to the dislocation positions, $d_{1}$ and $d_{2}$ as follows:

$\frac{\partial E_{\text {total }}}{\partial d_{1}}=\frac{\partial E_{\text {total }}}{\partial d_{2}}=0$.

Upon solving the set of Eq. (7), we obtain the CRSS as the minimum value of $\tau$ that satisfies both of these equations. The $\{110\}$ and $\{111\}$ twinning stresses obtained using Eq. (7) are included in Table 3 for all the alloys considered in the present analysis. Upon comparing the critical twinning stress values reported in Table 3, we observed that the twinning stress values for $\{111\}$ system are lower than the those for $\{110\}\langle 110\rangle$ system for most of the compositions, although the difference in magnitudes for both cases are within $10 \%$. Therefore, the twin systems observed in these alloys preferably belong to the $\{111\}$ plane.

\section{BCC $(\beta) \rightarrow$ Orthorhombic $\left(\alpha^{\prime \prime}\right)$ Transformation}

The $\beta-\alpha^{\prime \prime}$ transformation can be considered as a special case of the $\beta-\alpha^{\prime}$ (hcp) transformation, with the same 
(110) stacking sequence as in hcp structure but different lattice constants $[42,43]$. The lattice constants of the $\alpha^{\prime \prime}$ structure are between those of $\beta$ and $\alpha^{\prime}$ structures. The major difference between the two transformations lies in the principal deformation strains (Bain distortion matrix) to form the end state. The principal strains required to form the $\alpha^{\prime \prime}$ structure from the $\beta$ structure is identical in sense but differ only in magnitude compared to the $\beta-\alpha^{\prime}$ transformation [42, 43]. Consider the following Burgers lattice correspondence between the $\beta$ and the $\alpha^{\prime \prime}$ structure:

$[100]_{\beta}\left\|[100]_{\alpha^{\prime \prime}},[010]_{\beta}\right\|[01 \overline{1}]_{\alpha^{\prime \prime}},[001]_{\beta} \|[011]_{\alpha^{\prime \prime}}$.

As shown in Fig. 7, the $\alpha^{\prime \prime}$ structure can be formed from the $\beta$ structure via two deformation modes [44-47]: (i) Collinear shuffle displacements of alternating $\{110\}_{\text {bcc }}$ planes along $\langle 110\rangle_{\text {bcc }}$ direction by $\delta$ or alternatively, every second $\{110\}_{\text {bcc }}$ along $\langle 110\rangle_{\text {bcc }}$ direction by $2 \delta$ to form the orthorhombic stacking sequence and (ii) Bain deformation involving compression and dilation of $(110)_{\mathrm{bcc}}$ planes along $\langle 001\rangle$ and $\langle 110\rangle$ directions to achieve the lattice constants of the orthorhombic structure. In Fig. 7, we take $\mathrm{Ti}-6.25 \mathrm{Nb}-6.25 \mathrm{Ta}$ as an example to illustrate the magnitude of principal strains to achieve $\alpha^{\prime \prime}$ lattice constants from $\beta$ structure. The principal strains $\eta_{1}$ and $\eta_{2}$ are -2.8 and $+3.3 \%$ respectively, for $\mathrm{Ti}-6.25 \mathrm{Nb}-6.25 \mathrm{Ta}$.

The heterogeneous dislocation-based mechanism [48, 49] is well established for martensite transformation.
Consider the following dissociation reaction in a bcc crystal [48-50]:

$\frac{a}{2}[1 \overline{1} 1] \rightarrow \frac{a}{8}[0 \overline{1} 1]+\frac{a}{8}[0 \overline{1} 1]+\frac{a}{4}[2 \overline{1} 1]$.

When the dislocations with Burgers vector $b=\mathrm{a} / 8$ $\langle 011\rangle$ move on alternate $\{110\}$ bcc plane by an amount $\delta$, it forms the $\alpha^{\prime \prime}$ stacking sequence. The equilibrium shuffling displacement $(\delta)$ is calculated by minimizing the structural energy of the bcc crystal by varying shuffling displacement magnitudes. The complete list of shuffling displacements for all the alloys considered in the present analysis is provided in Table 7 . We then establish the energy per unit area required to shuffle the atoms on alternate $\{110\}$ planes by a displacement $\delta$ in terms of a fault energy $(\gamma)$ curve [51], and the results are shown in Fig. 8a. The term $\gamma_{\mathrm{sd} 1}^{\mathrm{u}}$ in Fig. 8a is the unstable fault energy required to shuffle the $N$ th layer of the crystal by a displacement of $\delta$. Similarly, $\gamma_{\mathrm{sd} 1}^{\mathrm{s}}$ is the stable fault energy per unit area corresponding to the shuffling of the same $N$ th layer by an additional displacement of $\delta$. The energy term $\gamma_{\mathrm{sd} 1}^{\mathrm{u}}$ represents the unstable energy required to shuffle the $(N+2)$ th layer by a displacement of $\delta$ and the term $\gamma_{\mathrm{sd} 2}^{\mathrm{s}}$ represents the stable energy corresponding to the additional shuffling of $(N+2)$ th layer by $\delta$. It is important to note that the dislocations participate in the collinear shuffling process during the martensitic transformation based on dislocationbased transformation theory [48, 49], while Bain
Fig. 7 Schematic of the process showing shear and shuffle mechanisms of transformation

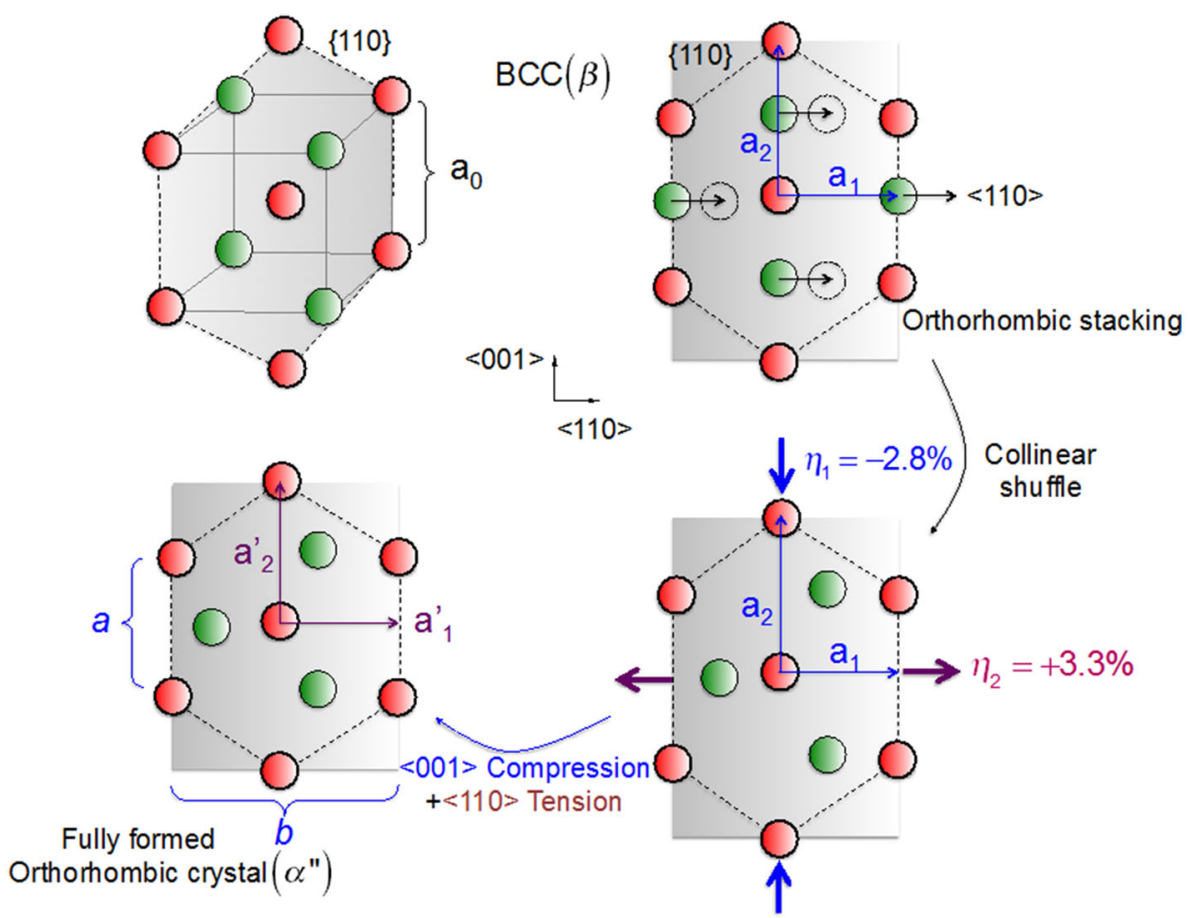


Table 7 The energy values (in $\mathrm{mJm}^{-2}$ ) associated with the shuffling for $\mathrm{Ti}-\mathrm{Nb}-\mathrm{Ta}$ alloys

\begin{tabular}{lllrlr}
\hline Compositions & $\delta(\AA)$ & $\gamma_{\mathrm{sd} 1}^{\mathrm{u}}$ & $\gamma_{\mathrm{sd} 1}^{\mathrm{s}}$ & $\gamma_{\mathrm{sd} 2}^{\mathrm{u}}$ & $\gamma_{\mathrm{sd} 2}^{\mathrm{s}}$ \\
\hline Ti-6.25Nb-6.25Ta & 0.33 & 219 & 63 & 248 & 55 \\
Ti-6.25Nb-18.75Ta & 0.33 & 313 & 74 & 322 & 58 \\
Ti-12.5Nb & 0.32 & 298 & 89 & 307 & 95 \\
Ti-12.5Nb-37.5Ta & 0.31 & 396 & 112 & 384 & 104 \\
Ti-18.75Nb & 0.29 & 198 & 76 & 256 & 113 \\
Ti-18.75Nb-25Ta & 0.28 & 237 & 154 & 223 & 126 \\
Ti-25Nb & 0.27 & 223 & 87 & 246 & 109 \\
Ti-25Nb-25Ta & 0.27 & 216 & 144 & 278 & 93 \\
Ti-25Ta & 0.35 & 228 & 126 & 285 & 123 \\
Ti-31.25Ta & 0.34 & 311 & 249 & 276 & 221 \\
Ti-37.5Ta & 0.34 & 323 & 246 & 298 & 213 \\
\hline
\end{tabular}

The shuffling displacements $(\delta)$ are also provided

deformation does not involve any dislocation activity. The Bain deformation is accomplished via internal stresses inherently present in the crystal due to inclusions or imperfections [48, 49]. This has been further supported by molecular dynamics simulations [52]. In addition, these simulations have shed light on the role of dislocations, in the absence of which no transformation was observed [50]. Furthermore, in the current study, we employ dislocationbased martensite transformation mechanism, and therefore shuffling process involving dislocations is accounted for in our theoretical modeling. As will be seen next, the compression or dilation event does not contribute to the total energy of the dislocation in our formulation.

We write the total energy of the dislocations as the sum of (i) the elastic energy due to interaction of the dislocations, $E_{\text {int }}$; (ii) the self-energy of the dislocations, $E_{\text {self }}$; (iii) the misfit energy $\left(E_{\gamma}^{\mathrm{s}}\right)$ which represents the periodic energy that should be overcome by the dislocation; and (iv) the applied work, $W$, to move the dislocations. Therefore, the total energy of the dislocation configuration in Fig. $8 \mathrm{~b}$ can be written as follows:

$$
\begin{aligned}
E_{\mathrm{total}}= & E_{\mathrm{int}}+E_{\mathrm{self}}+E_{\gamma}^{\mathrm{s}}-W \\
= & -\frac{G b^{2}}{2 \pi} \ln \left(\frac{2 \delta}{r_{o}}\right)+N \frac{G b^{2}}{2(1-v)}\left(1-v \cos ^{2} \theta\right) \\
& +\int_{-\infty}^{+\infty} \gamma[f(x)] d x-2 N \tau b \delta
\end{aligned}
$$

where $E_{\text {self }}+E_{\text {int }}\left(=E_{\text {elastic }}\right)$ is the elastic strain energy stored in the two half crystals, $E_{\gamma}^{s}$ is the misfit energy representing the periodic non-linear interatomic interactions in the dislocation core, $G$ is the shear modulus, and $N$ is the number of dislocations participating in the transformation process. The term $f(\mathrm{x})$ is obtained in a similar manner as described in "Generalized Stacking Fault Energy and Austenite Slip" and "Modeling of the Twinning Stress" sections. The critical transformation stress is then obtained by minimizing the total energy with respect to the shuffling displacement as follows:

$\frac{\partial E_{\text {total }}}{\partial \delta}=0$.

The critical transformation stress for all the alloys obtained using Eq. (9) is provided in Table 3.

\section{Discussion of the Results}

Considerable effort has been devoted in establishing the CRSS for (i) austenite slip, (ii) $\beta$ to $\alpha^{\prime \prime}$ transformation, and (iii) the martensite twinning as a function of $\mathrm{Nb}$ and $\mathrm{Ta}$ contents in the present work. The determination of these quantities is accomplished through in-depth investigation of the associated energy barriers (GPFE and the GSFE), the
Fig. 8 (a) Fault energy curve $(\gamma$-curve) associated with shuffling process during bec to orthorhombic transformation for the case of $\mathrm{Ti}-6.25 \mathrm{Nb}-6.25 \mathrm{Ta}$

(b) Schematic of the dislocation based martensite transformation.

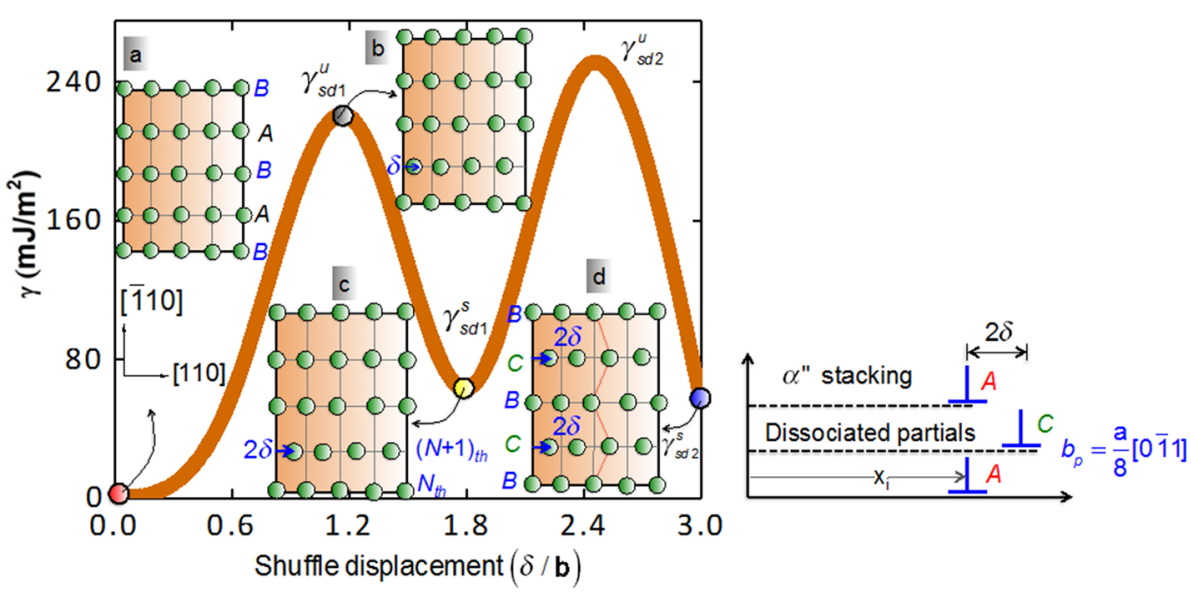

(a) (b) 
lattice constants, and the shear moduli of the slip and the twin systems. Since the twinning/detwinning of the martensite crystal, the austenite slip, and the transformation stress magnitudes govern the shape memory effect and superelastic properties, it is important to theoretically develop models to calculate these quantities, which we successfully undertake in this study. The theoretical models do not rely on any empirical constants, and therefore, they provide useful insights into the development of $\mathrm{Ti}-\mathrm{Nb}-\mathrm{Ta}$ with novel alloying compositions.

The role of slip dislocations during phase transformation has been extensively studied in NiTi [30-32] and $\mathrm{CuNiAl}$ $[33,34]$. The austenite to martensite phase transformation is associated with high internal stresses and strains, especially at the phase interface, which acts as the dislocation source [53-55]. Slip dislocations are also found to originate due to the interaction of martensite plates during phase transformation [34]. The dislocations emanating from the interface are found to be aligned with the martensite twin planes [53]. In this regard, microstructural evidence [32, 54] has shown that the dislocation multiplication, and hence its density is high in austenite close to the austenite/martensite interface during stress-induced martensite transformation. Twinning is one of the mechanisms to relieve the incompatible strains at the interfaces; however, the internal stresses accompanied with external stress are high enough to generate numerous dislocation bundles which introduce permanent plastic strain in SMAs. In some of the Ti-based alloys, even voids are found to nucleate from the interface, as validated by fractography analysis [17].

The dislocation slip has been investigated in $\beta$-titanium alloy using TEM analysis [16]. The dislocations with Burgers vector $b=a / 2\langle 111\rangle$ are observed to glide on the $\{110\},\{112\}$, and $\{123\}$ planes similar to bcc metals, and the deformation is largely governed by the motion of screw segments. The mobile screw dislocations on $\{112\}$ and $\{123\}$ planes are found to frequently cross slip onto the $\{110\}$ plane, the latter being the preferential glide plane in these alloys [16]. An issue with slips observed during phase transformation is their contribution to hysteresis [54], thus degrading the functionality of SMAs. Slips are observed to interact with the austenite-martensite interface, and increase the resistance of the interfacial motion of the martensite during phase transformation process. However, experiments have also shown that dislocations formed during plastic deformation of martensite are found to promote the growth of martensite depending on the type of dislocation, as in the case of CuNiAl [34] and NiTi [30]. In any case, the CRSS magnitude for slip and its comparison with the transformation/twinning stress magnitudes is an important topic in order to understand the plasticity associated with SMAs, which we undertook in this study for the case of $\mathrm{Ti}-\mathrm{Nb}$-based alloys.

The importance of the shuffling process during martensitic transformation has been discussed in the literature [44-47]. It has been proposed that the compositiondependent shuffling process may have a significant effect on the elastic moduli of $\mathrm{Ti}-\mathrm{Nb} \alpha^{\prime \prime}$ crystal [46]. In addition, the Ti-rich $\omega$-phase formed by aging at low to intermediate temperature or by quenching increases the elastic moduli in addition to suppressing the martensitic transformation [3]. The $\omega$-phase also decreases the transformation temperature $M_{\mathrm{s}}$, and consequently increases the critical transformation stress. It is important to note that our transformation stress analysis is applicable to $\beta-\alpha^{\prime \prime}$ phase transformation, and the effect of $\omega$-phase is not taken into consideration.

Recently, X-ray diffraction measurements [46] have revealed the role of the composition dependence on the Bain distortion and the shuffling magnitude in $\mathrm{Ti}-\mathrm{Nb}$. The dependence of the Bain distortion on the composition is obvious, as the orthorhombic lattice constants are strongly dependent on $\mathrm{Nb}$ content (see Table 1). Therefore, the magnitudes of principal strains to achieve the lattice constants of the orthorhombic phase depend on the $\mathrm{Nb}$ content. Experimentally, the magnitude of the shuffling displacement is found to show a linear dependence on the $\mathrm{Nb}$ content with composition 10-40 at.\% [45, 46]. If we investigate the shuffling displacement magnitudes we obtained in the present case (Table 7), we find that $\mathrm{Nb}$ predominantly governs the shuffling displacement magnitudes, while Ta shows negligible effect. In fact, the shuffling magnitudes decrease with an increase in $\mathrm{Nb}$ content from Table 7. It is worth pointing out that the transformation stress calculation we employ in the present analysis is based on the heterogeneous dislocation-based mechanism of martensite transformation [48, 49] where dislocations partake in the shuffling process. It should be noted that fault created by the $a / 8\langle 110\rangle$ dislocations during shuffling stage make the bcc phase much closer to the orthorhombic phase, thus reducing the transformation barrier as observed in other Ti-alloy [52]. Molecular dynamics simulations [50] have also shown that dislocations are responsible for the early stage of martensite transformation (shuffling), while the later stages of the transformation involving Bain deformation require no dislocation activities. The latter is assisted by internal stresses inherently present in the lattice due to imperfections (such as inclusions).

It is well known that self-accommodating internally twinned martensite variants are responsible for minimizing the incompatible strains associated with martensitic transformation [39, 56]. The martensitic plates are coherent (show no misfit dislocations) and ensure the reversibility of 
phase during twinning/detwinning process [39]. In this regard, the twinning process in $\mathrm{Ti}-\mathrm{Nb}-\mathrm{Ta}$ is an important topic to investigate, which we discussed in the current paper. It is interesting to note that $\{110\}$ twin formation in $\mathrm{Ti}-\mathrm{Nb}-\mathrm{Ta}$ alloys is accomplished through coupled shear and shuffle during which the atoms undergo local rearrangement to lower and stabilize the GPFE curve. Although the internal shuffling mechanism in B19 NiTi has been well discussed in the literature $[57,58]$, that of Ti$\mathrm{Nb}-\mathrm{Ta}$ is still unknown. In order to determine the dominant shuffle mode in $\mathrm{Ti}-\mathrm{Nb}-\mathrm{Ta}$ alloys, we calculated the minimum structural energy for two different shuffling modes. The first shuffling mode as shown in Fig. 4 involves the motion of atoms in $(010)_{\mathrm{B} 19}$ plane along the $[001]_{\mathrm{B} 19}$ direction, while the second shuffling mode corresponds to $(001)[100]_{\mathrm{B} 19}$ system. For these two cases, the total structural energy in the case of Ti-6.25Nb-6.25Ta was found to be -129.43 and $-128.88 \mathrm{eV}$, respectively, showing that $(010)[001]_{\mathrm{B} 19}$ shuffling mode is dominant. In addition, although the twinning shear values $(s)$ and the $\gamma_{\mathrm{ut}}$ values for the case of $\{111\}$ twin are much higher than those for $\{110\}$ for the same composition, the higher magnitude of the Burgers vector for $\{110\}$ twinning dislocation results in a lower stress magnitude compared to the $\{110\}$ case, as evident from Eq. (4). Upon comparing the values in Tables 4 and 6, we observe that the Burgers vector for $\{111\}$ twinning is almost four times higher than that for $\{110\}$ case, while the shear moduli are within $10 \%$ for the same composition. Therefore, the lower twinning stress magnitudes for the case of $\{111\}$ twins compared to $\{110\}$ twins are strongly attributed to the higher magnitudes of the Burgers vector of the twinning dislocation. Nonetheless, the critical twinning stress values increase with an increase in $\gamma_{\mathrm{ut}}$ for $\{111\}$ twins, similar to the ones observed for the case of $\{110\}$ twins.

The twinnability approach $[59,60]$ has been used in cubic crystals utilizing the energy barriers to investigate the competition between slip and twinning, and our calculations show that the martensite crystal prefers to twin than to nucleate a slip dislocation. If we compare $\gamma_{\text {us }}$ required to nucleate a slip versus $\gamma_{\text {us }}$ required to nucleate a twin, the $\gamma_{\text {us }}$ for slip is found to be higher than $\gamma_{\text {us }}$ for twin suggesting that twin formation is easier than deformation by slip to a first approximation for all of the alloys considered. For example, the $\gamma_{\text {us }}$ for slip in Ti-6.25Nb-6.25Ta is 460 $\mathrm{mJm}^{-2}$ and $\gamma_{\text {us }}$ for twin is $364 \mathrm{mJm}^{-2}$, the former being as high as 1.3 times the latter. The low energy barriers associated with twinning and transformation assist reversible transformation, thus minimizing permanent plastic deformation over all compositions considered in the present analysis.

In order to compare and understand the alloying effects on the CRSS for slip, transformation, and twinning, we plot the CRSS as a function of $\mathrm{Nb}$ and Ta content in Fig. 9. It is important to note that that all of these quantities increase with increase in Ta content. However, the rate of increase of CRSS with an increase in Ta content is much higher for slip compared to transformation and twinning, thus the difference between the two increasing with an increase in Ta content. The higher CRSS of austenite slip compared to transformation stress is beneficial to improve the shape memory response. In such a case of high austenite slip stress, the transformation proceeds at a stress much lower compared to the austenite slip stress, and hence the possibility of any plastic strain accumulation is minimized. In the present calculation, the difference between the transformation and the austenite slip resistance is as high as $158 \mathrm{MPa}$ for the case of Ti-25Nb-25Ta, and this alloy may show promising shape memory response. Overall, we find that higher alloying content exhibits higher difference between the austenite slip and the transformation stress.

We point out to the major variables affecting the slip and the twinning stresses in the current study. Upon analyzing Tables 2 and 3, we note that an increase in $\gamma_{\text {us }}$ increases the shear moduli, and eventually the slip stress in austenite $\mathrm{Ti}-\mathrm{Nb}-\mathrm{Ta}$ crystals. Recently [10], we obtained similar results for the case of martensite slip resistance in both $\mathrm{Ti}-\mathrm{Nb}-\mathrm{Ta}$ and $\mathrm{Ti}-\mathrm{Nb}-\mathrm{Zr}$ alloys where an increase in $\gamma_{\text {us }}$ is found to increase the slip stress magnitudes. Similarly, the martensite twinning stress is found to depend on one major variable- the unstable twinning fault energy $\left(\gamma_{\mathrm{ut}}\right)$, as shown in Fig. 10. The dependence of twinning stress on the intrinsic stacking fault energy $\left(\gamma_{\text {isf }}\right)$, however, is not so pronounced, as evident from Fig. 10 in Ti-Nb-Ta alloys. It is important to note that the twinning stress dependence of orthorhombic Ti-Nb-Ta alloy on $\gamma_{u t}$ is similar to fcc metals [61]. Reassessing the GPFE values in Table 5, we observe that $\gamma_{\text {us }}$ associated with twinning do not show any observable dependence on alloying compositions in $\mathrm{Ti}-\mathrm{Nb}-\mathrm{Ta}$ alloys.

Experiments $[1,3]$ on binary $\mathrm{Ti}-\mathrm{Nb}$ alloys have shown that a decrease in $\mathrm{Nb}$ content increases the critical stress to induce martensite transformation. The $\mathrm{Ti}-25 \mathrm{Nb}$ alloy exhibits shape memory with complete strain recovery of approximately $2.2 \%[1,3]$. This can be rationalized based on the high-martensite slip resistance and much lower twinning stress in $\mathrm{Ti}-25 \mathrm{Nb}$. Our calculations show that the critical twinning stress of $\mathrm{Ti}-25 \mathrm{Nb}$ is $72 \mathrm{MPa}$, which is lower than the CRSS of martensite slip by $156 \mathrm{MPa}$, and hence the alloy exhibits complete strain recovery without undergoing any plasticity. Experimentally [1, 3], the twinning stress of $\mathrm{Ti}-25 \mathrm{Nb}$ is obtained to be $170 \mathrm{MPa}$ based on $0.2 \%$ strain offset. If we assume that Schmid factor of the twin system is 0.5 , the experimentally determined CRSS for $\mathrm{Ti}-25 \mathrm{Nb}$ is $85 \mathrm{MPa}$, which is within $15 \%$ of the theoretical value we obtained in the present analysis. 


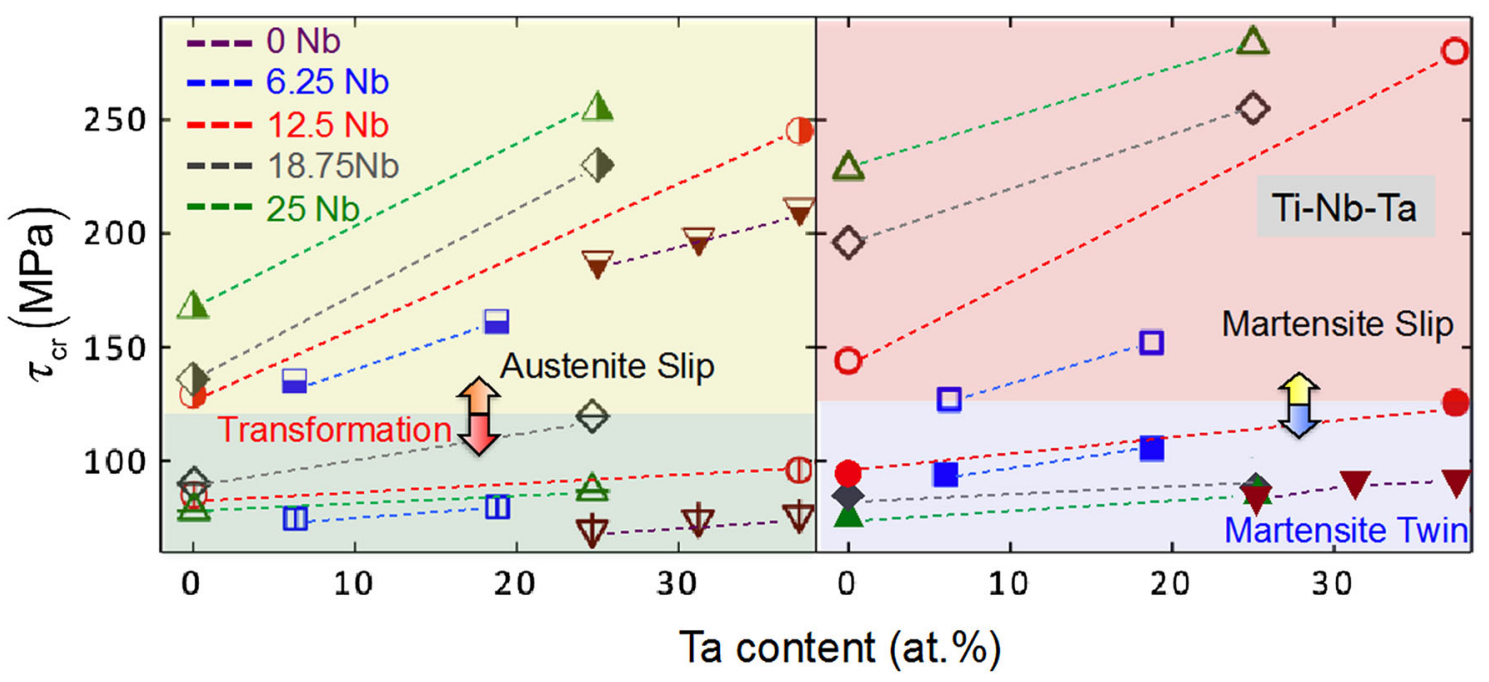

Fig. 9 Dependence of the CRSS for austenite and martensite slips, twinning, and transformation stresses on Ta content for Ti-Nb-Ta alloys. The slip in austenite occurs on $\{110\}\langle 111\rangle$ system, while the slip in martensite occurs on $\{100\}\langle 100\rangle$ system. Similarly, the twinning on martensite $\mathrm{Ti}-\mathrm{Nb}-\mathrm{Ta}$ alloys is observed on the $\{111\}$ plane

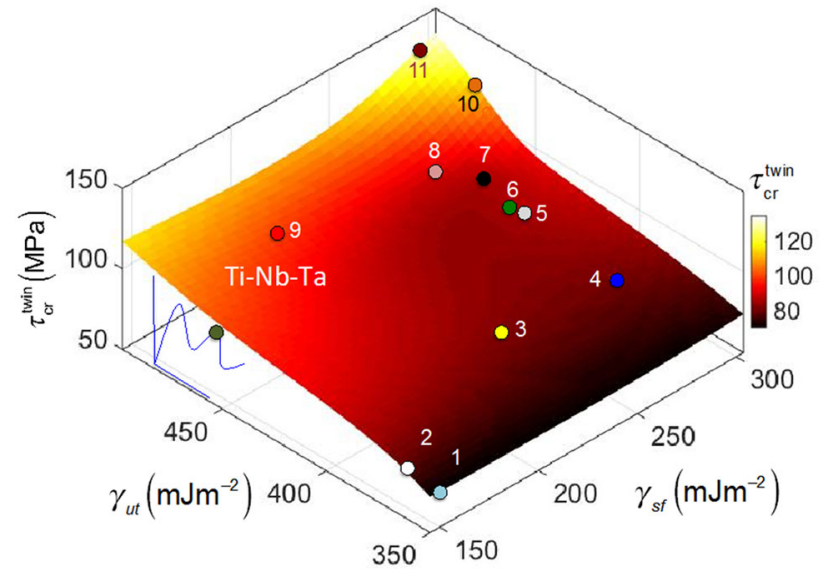

Fig. 10 Dependence of the minimum twinning stress on in $\mathrm{Ti}-\mathrm{Nb}-\mathrm{Ta}$ alloys. The following number designations are used in the figure: 1 $\mathrm{Ti}-25 \mathrm{Nb}, 2 \mathrm{Ti}-18.75 \mathrm{Nb}, 3 \mathrm{Ti}-25 \mathrm{Nb}-25 \mathrm{Ta}, 4 \mathrm{Ti}-25 \mathrm{Ta} 5 \mathrm{Ti}-31.25 \mathrm{Nb}$, $6 \mathrm{Ti}-37.5 \mathrm{Ta}, 7 \mathrm{Ti}-18.75 \mathrm{Nb}-25 \mathrm{Ta}, 8 \mathrm{Ti}-12.5 \mathrm{Nb}, 9 \mathrm{Ti}-6.25 \mathrm{Nb}-$ 6.25Ta, $10 \mathrm{Ti}-6.25 \mathrm{Nb}-18.75 \mathrm{Ta}, 11 \mathrm{Ti}-12.5 \mathrm{Nb}-37.5 \mathrm{Ta}$

Similarly, assuming that the $\mathrm{SF}$ is 0.5 , the martensite critical slip stress and the twinning stress for Ti-8Nb-20Ta are approximately 175 and $150 \mathrm{MPa}$, respectively, from experiments, the difference between the two as low as $25 \mathrm{MPa}$. If we compare these values with the theoretically observed magnitudes for similar composition of $\mathrm{Ti}$ and $\mathrm{Ta}$, the martensite critical slip stress is approximately $152 \mathrm{MPa}$, while the twinning stress is $106 \mathrm{MPa}$. The theoretically observed difference between the martensite slip stress and the twinning stress from our calculations is $46 \mathrm{MPa}$, while experimentally observed magnitude is $25 \mathrm{MPa}$, thus reflecting good agreement.

\section{Conclusion}

We draw the following conclusions from the current paper:

(1) We developed theoretical models to establish the three important parameters: (i) the CRSS for austenite slip, (ii) CRSS for martensite twinning, and (iii) the critical $\beta-\alpha^{\prime \prime}$ transformation stress governing shape memory and superelasticity in $\mathrm{Ti}-$ $\mathrm{Nb}-\mathrm{Ta}$ alloys for 11 different compositions of $\mathrm{Nb}$ and Ta.

(2) We established the fault energy curves for transformation, GSFE and GPFE for slip and twinning, and utilized modified Peierls Nabarro formalism and dislocation-based martensite nucleation theory to establish the CRSS values.

(3) The current work points out to the major variables such as lattice constants, Burgers vector, shear moduli, and twinning shear that affect the stress magnitudes. Specially, the austenite slip was found to strongly depend on shear moduli and $\gamma_{\text {us }}$ values. Similarly, the twinning stress magnitudes increase with an increase in the unstable twinning fault energy $\left(\gamma_{\mathrm{ut}}\right)$, similar to pure fcc metals.

(4) We revealed that $\{110\}\langle 110\rangle$ twin formation in B19 $\mathrm{Ti}-\mathrm{Nb}-\mathrm{Ta}$ alloys is accomplished through coupled shear and shuffle, while $\{111\}$ twin is formed by shear alone. Two different shuffling modes, $(010)[001]_{\mathrm{B} 19}$ and $(001)[100]_{\mathrm{B} 19}$, were investigated for $\{110\}\langle 110\rangle$ twinning, and our results indicated that the former is dominant in $\mathrm{Ti}-\mathrm{Nb}-\mathrm{Ta}$ alloys due to the low structural energy $(-129.43 \mathrm{eV}$ for $(010)[001]_{\mathrm{B} 19}$ vs. $-128.88 \mathrm{eV}$ for $\left.(001)[100]_{\mathrm{B} 19}\right)$. 
(5) We find that the dependence of CRSS on Ta content is greater for the case of slip compared to twinning or transformation. Our calculations showed that an increase in Ta content from 0 to 37.5 at.\% increases the CRSS for austenite and martensite slip by more than $90 \%$, while the twinning stress increases by $25 \%$, and the transformation stress by $40 \%$ for the same composition of $\mathrm{Ta}$ and $\mathrm{Nb}$.

(6) We also show that the CRSS values for slip nucleation in martensite are close to those of austenite for most of the compositions, differing only by $10 \%$. However, these values are much higher than the twinning or the transformation stresses. Overall, as the Ta composition increases, the difference between martensite/austenite slip and the transformation/twinning stress increases. This is important for better shape memory and superelastic properties for high-temperature applications.

Acknowledgments The work is supported by the Nyquist Chair Funds and partially by the National Science Foundation Grant NSF CMMI-1333884 which are gratefully acknowledged.

\section{References}

1. Kim HY, Fu J, Tobe H, Kim JI, Miyazaki S (2015) Crystal structure, transformation strain, and superelastic property of $\mathrm{Ti}-\mathrm{Nb}-\mathrm{Zr}$ and Ti-Nb-Ta alloys. Shape Mem Superelasticity 1:107-116

2. Kim HY, Hashimoto S, Kim JI, Inamura T, Hosoda H, Miyazaki $\mathrm{S}$ (2006) Effect of Ta addition on shape memory behavior of Ti22Nb alloy. Mater Sci Eng A 417:120-128

3. Kim HY, Ikehara Y, Kim JI, Hosoda H, Miyazaki S (2006) Martensitic transformation, shape memory effect and superelasticity of Ti-Nb binary alloys. Acta Mater 54:2419-2429

4. Kim HY, Kanaya T, Fukushima T, Bueconsejo PJS, Miyazaki S (2012) Stability of Ti-Ta base high temperature shape memory alloys. Materials Science Forum: Trans Tech Publ, Pfaffikon. p 1921-1924

5. Kim JI, Kim HY, Hosoda H, Miyazaki S (2005) Shape memory behavior of Ti-22Nb-(0.5-2.0) O (at\%) biomedical alloys. Mater Trans 46:852-857

6. Miyazaki S, Kim HY, Hosoda H (2006) Development and characterization of $\mathrm{Ni}$-free $\mathrm{Ti}$-base shape memory and superelastic alloys. Mater Sci Eng A 438:18-24

7. Hao YL, Li SJ, Sun SY, Zheng CY, Hu QM, Yang R (2005) Super-elastic titanium alloy with unstable plastic deformation. Appl Phys Lett 87:091906

8. Ozaki T, Matsumoto H, Watanabe S, Hanada S (2004) Beta Ti alloys with low young's modulus. Mater Trans 45:2776-2779

9. Kim JI, Kim HY, Inamura T, Hosoda H, Miyazaki S (2005) Shape memory characteristics of $\mathrm{Ti}-22 \mathrm{Nb}-(2-8) \mathrm{Zr}$ (at.\%) biomedical alloys. Mater Sci Eng A 403:334-339

10. Ojha A, Sehitoglu H (2016) Slip resistance of Ti-based hightemperature shape memory alloys. Shap Mem Superelasticity 1-12. doi:10.1007/s40830-015-0050-z

11. Tahara M, Kim HY, Inamura T, Hosoda H, Miyazaki S (2009) Effect of nitrogen addition on superelasticity of Ti-Zr-Nb alloys. Mater Trans 50:2726-2730
12. Karaman I, Sehitoglu H, Beaudoin AJ, Chumlyakov YI, Maier HJ, Tome CN (2000) Modeling the deformation behavior of Hadfield steel single and polycrystals due to twinning and slip. Acta Mater 48:2031-2047

13. Ogata S, Li J, Yip S (2005) Energy landscape of deformation twinning in bcc and fcc metals. Phys Rev B 71:224102

14. Ojha A, Sehitoglu H (2014) Twinning stress prediction in bcc metals and alloys. Philos Mag Lett 94:647-657

15. Ojha A, Sehitoglu H, Patriarca L, Maier HJ (2014) Twin nucleation in Fe-based bcc alloys-modeling and experiments. Model Simul Mater Sci Eng 22:075010

16. Castany P, Besse M, Gloriant T (2012) In situ TEM study of dislocation slip in a metastable $\beta$ titanium alloy. Scr Mater 66:371-373

17. Mythili R, Saroja S, Vijayalakshmi M (2007) Study of mechanical behavior and deformation mechanism in an $\alpha-\beta \mathrm{Ti}-4.4 \mathrm{Ta}-$ $1.9 \mathrm{Nb}$ alloy. Mater Sci Eng A 454:43-51

18. Xu W, Kim KB, Das J, Calin M, Eckert J (2006) Phase stability and its effect on the deformation behavior of Ti-Nb-Ta-In/Cr $\beta$ alloys. Scr Mater 54:1943-1948

19. Xu W, Kim KB, Das J, Calin M, Rellinghaus B, Eckert J (2006) Deformation-induced nanostructuring in a Ti-Nb-Ta-In $\beta$ alloy. Appl Phys Lett 89:031906

20. Kim HY, Oshika N, Kim JI, Inamura T, Hosoda H, Miyazaki S (2007) Martensitic transformation and superelasticity of Ti-Nb-Pt alloys. Mater Trans 48:400-406

21. Buenconsejo PJS, Kim HY, Hosoda H, Miyazaki S (2009) Shape memory behavior of Ti-Ta and its potential as a high-temperature shape memory alloy. Acta Mater 57:1068-1077

22. Carrez P, Ferré D, Cordier P (2007) Peierls-Nabarro model for dislocations in $\mathrm{MgSiO}_{3}$ post-perovskite calculated at $120 \mathrm{GPa}$ from first principles. Philos Mag 87:3229-3247

23. Joos B, Duesbery MS (1997) The Peierls stress of dislocations: an analytic formula. Phys Rev Lett 78:266

24. Joós B, Ren Q, Duesbery MS (1994) Peierls-Nabarro model of dislocations in silicon with generalized stacking-fault restoring forces. Phys Rev B 50:5890-5898

25. Lu G, Kioussis N, Bulatov VV, Kaxiras E (2000) The peierlsnabarro model revisited. Philos Mag Lett 80:675-682

26. Peierls R (1940) The size of a dislocation. Proc Phys Soc 52:34

27. Schoeck G (2011) The Peierls stress in a simple cubic lattice. Phys Status Solidi B 248:2284-2289

28. Wang J, Sehitoglu H (2014) Modelling of martensite slip and twinning in NiTiHf shape memory alloys. Philos Mag 94:2297-2317

29. Vitek V (1968) Intrinsic stacking faults in body-centred cubic crystals. Philos Mag 18:773-786

30. Norfleet DM, Sarosi PM, Manchiraju S, Wagner M-X, Uchic MD, Anderson PM et al (2009) Transformation-induced plasticity during pseudoelastic deformation in Ni-Ti microcrystals. Acta Mater 57:3549-3561

31. Simon T, Kröger A, Somsen C, Dlouhy A, Eggeler G (2010) On the multiplication of dislocations during martensitic transformations in NiTi shape memory alloys. Acta Mater 58:18501860

32. Gall K, Sehitoglu H, Chumlyakov YI, Kireeva IV (1998) Pseudoelastic cyclic stress-strain response of over-aged single crystal Ti-50.8 at\% Ni. Scr Mater 40:7-12

33. Sun Q-P, Xu TT, Zhang X (1999) On deformation of AM interface in single crystal shape memory alloys and some related issues. J Eng Mater Technol 121:38-43

34. Ibarra A, San Juan J, Bocanegra EH, Nó ML (2007) Evolution of microstructure and thermomechanical properties during superelastic compression cycling in $\mathrm{Cu}-\mathrm{Al}-\mathrm{Ni}$ single crystals. Acta Mater 55:4789-4798 
35. Kresse G, Furthmüller J (1996) Efficient iterative schemes for ab initio total-energy calculations using a plane-wave basis set. Phys Rev B 54:11169-11186

36. Kresse G, Hafner J (1993) Ab initio molecular dynamics for open-shell transition metals. Phys Rev B 48:13115-13118

37. Huang J, Xing H, Sun J (2012) Structural stability and generalized stacking fault energies in $\beta \mathrm{Ti}-\mathrm{Nb}$ alloys: relation to dislocation properties. Scr Mater 66:682-685

38. Wang J, Sehitoglu H (2013) Twinning stress in shape memory alloys: theory and experiments. Acta Mater 61:6790-6801

39. Chai YW, Kim HY, Hosoda H, Miyazaki S (2009) Self-accommodation in $\mathrm{Ti}-\mathrm{Nb}$ shape memory alloys. Acta Mater 57:4054-4064

40. Bertrand E, Castany P, Yang Y, Menou E, Gloriant T (2016) Deformation twinning in the full- $\alpha^{\prime \prime}$ martensitic Ti-25Ta-20Nb shape memory alloy. Acta Mater 105:94-103

41. Ping DH, Yamabe-Mitarai Y, Cui CY, Yin FX, Choudhry MA (2008) Stress-induced alpha. Appl Phys Lett 93:1911

42. Duerig TW, Williams JC (1980) Overview: microstructure and properties of beta titanium alloys. In: Eylon D, Boyer RR, Koss DA (eds) Beta titanium alloys in the 1980's 1983. American Society for Metals, Metals Park, pp 19-67

43. Duerig TW, Middleton RM, Terlinde GT, Williams JC (1980) Stress assisted transformation in Ti-10V-2Fe-3Al. Defense Technical Information Center

44. Ahmed T, Rack HJ (1996) Martensitic transformations in Ti(16-26 at\%) Nb alloys. J Mater Sci 31:4267-4276

45. Banumathy S, Mandal RK, Singh AK (2009) Structure of orthorhombic martensitic phase in binary $\mathrm{Ti}-\mathrm{Nb}$ alloys. J Appl Phys 106:093518

46. Bönisch M, Calin M, Giebeler L, Helth A, Gebert A, Skrotzki W et al (2014) Composition-dependent magnitude of atomic shuffles in Ti-Nb martensites. J Appl Crystallogr 47:1374-1379

47. Moffat DL, Larbalestier DC (1988) The compctition between martensite and omega in quenched Ti-Nb alloys. Metall Trans A 19:1677-1686

48. Olson GB, Cohen M (1976) A general mechanism of martensitic nucleation: part II. FCC $\rightarrow$ BCC and other martensitic transformations. Metall Trans A 7:1905-1914
49. Olson GB, Cohen M (1976) A general mechanism of martensitic nucleation: part I. General concepts and the FCC $\rightarrow$ HCP transformation. Metall Trans A 7:1897-1904

50. Kuznetsov AR, Gornostyrev YN, Katsnelson MI, Trefilov AV (2001) Effect of the dislocations on the kinetics of a martensitic transition: MD simulation of bcc-hcp transformation in Zr. Mater Sci Eng A 309:168-172

51. Ojha A, Sehitoglu H (2016) Critical stress for the bcc-hcp martensite nucleation in Ti-6.25 at.\% Ta and Ti-6.25 at.\% Nb alloys. Comput Mater Sci 111:157-162

52. Grujicic M, Dang P (1996) Atomic-scale analysis of martensitic transformation in titanium alloyed with vanadium Part II: molecular dynamics simulations. Mater Sci Eng A 205:153-165

53. Hurley J, Ortega AM, Lechniak J, Gall K, Maier HJ (2003) Structural evolution during the cycling of NiTi shape memory alloys. Dedicated to Professor Dr. Otmar Vöhringer on the occasion of his 65th birthday. Zeitschrift für Metallkunde 94:547-552

54. Hamilton RF, Sehitoglu H, Chumlyakov Y, Maier HJ (2004) Stress dependence of the hysteresis in single crystal NiTi alloys. Acta Mater 52:3383-3402

55. Sehitoglu H, Zhang XY, Kotil T, Canadinc D, Chumlyakov Y, Maier HJ (2002) Shape memory behavior of FeNiCoTi single and polycrystals. Metall Mater Trans A 33:3661-3672

56. Saburi T, Wayman CM (1979) Crystallographic similarities in shape memory martensites. Acta Metall 27:979-995

57. Zhong Y, Gall K, Zhu T (2012) Atomistic characterization of pseudoelasticity and shape memory in NiTi nanopillars. Acta Mater 60:6301-6311

58. Otsuka K, Ren X (1999) Martensitic transformations in nonferrous shape memory alloys. Mater Sci Eng A 273:89-105

59. Bernstein N, Tadmor EB (2004) Tight-binding calculations of stacking energies and twinnability in fcc metals. Phys Rev B 69:094116

60. Tadmor EB, Bernstein N (2004) A first-principles measure for the twinnability of FCC metals. J Mech Phys Solids 52:2507-2519

61. Kibey S, Liu JB, Johnson DD, Sehitoglu H (2007) Predicting twinning stress in fcc metals: linking twin-energy pathways to twin nucleation. Acta Mater 55:6843-6851 